\title{
Research Paper: Effects Hospital Incident Command System Establishment on Disaster Preparedness of Tehran Hospitals Affiliated to Law Enforcement Staff Under Simulated Conditions
}

\author{
Hamidreza Khankeh $^{1} \mathbb{D}$, Mahtab Lotfolahbeygi ${ }^{1} \mathbb{D}$, Asghar Dalvandi ${ }^{1} \mathbb{D}$, Nasir Amanat ${ }^{2 *}$ (D) \\ 1. Department of Nursing, University of Social Welfare and Rehabilitation Sciences, Tehran, Iran. \\ 2. Research Center in Emergency and Disaster Health, University of Social Welfare and Rehabilitation Sciences, Tehran, Iran.
}

Funding: See Page 212

(c) Copyright: The Author(s)

Article info:

Received: 28 Oct. 2017

Accepted: 10 Feb. 2018

Available Online: 01 Jul. 2018

\section{Keywords:}

Preparedness, Hospital Incident Command System, Disasters
Citation: Khankeh HR, Lotfolahbeygi M, Dalvandi A, Amanat N. Effects Hospital Incident Command System Establishment on Disaster Preparedness of Tehran Hospitals Affiliated to Law Enforcement Staff Under Simulated Conditions. Health in Emergencies and Disasters Quarterly. 2018; 3(4):207-214.

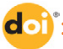

\begin{abstract}
A B S T R ACT
Background: Hospitals as the essential health service providers should manage their performance during incidents and disasters. The Hospital Incident Command System (HICS) is helpful in this regard. The establishment of this system assists the hospital disaster risk management committee to get prepared in emergency situations. This study aimed to assess the effect of HICS establishment on preparedness of Police Hospitals in Tehran, Iran during disasters, under simulated conditions.
\end{abstract}

Materials and Methods: This was a quasi-experimental interventional study. The study participants were 55 managers of Imam Sajjad and Vali Asr hospitals in Tehran selected by census method (23 from Imam Sajjad Hospital as the control group, and 32 from Vali Asr Hospital as the experimental group). The preparedness of hospitals was measured before the intervention using Hospital Preparedness Scale (HPS) designed by Khankeh (2012). After establishment of HICS in Vali Asr Hospital, the hospital managers received a 3-day training through incident scenario. After one month, their preparedness was measured again by HPS instrument. The collected data were analyzed in SPSS (Version 18) using descriptive statistics, Independent $t$ test and Chi-square test.

Results: Establishment of HICS significantly increased preparedness of hospitals in communications, continuity of vital services, manpower, and procurement and logistics areas.

Conclusion: Establishment of HICS can improve the hospitals' preparedness at times of disasters in many aspects. It is suggested that similar studies be conducted in private and public hospitals with longer follow-up time.

\footnotetext{
* Corresponding Author:

Nasir Amanat, MSc.

Address: Research Center in Emergency and Disaster Health, University of Social Welfare and Rehabilitation Sciences, Tehran, Iran

E-mail: nasir23a@hotmail.com
} 


\section{Introduction}

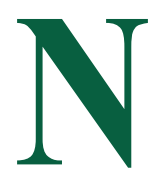

atural disasters and man-made incidents affect a large number of people worldwide and their impact has increased over the past decade [1]. These are often uncontrollable events that occur around the world [2]. Hospitals as the essential health service providers should manage their performance during disasters [3, 4]. These centers which play an important role in the treatment of injuries in times of disaster, require proper arrangement [2].

Accidents and disasters can cause many mortalities. Since 1990, about 1.6 million people have died due to accidents, which equals about 65000 per year [5]. Since hospitals must continue the provision of health care services in disaster response, and hospital preparedness is achievable only through a team work and coordination of all key sectors, a proper plan and a common standard system are required as the main factors in this regard [6].

Of all accountable medical personnel in accidents and disasters, nurses are among the most important treatment groups that should be prepared, therefore, they must acquire the knowledge and abilities necessary to work during accidents and disasters [7] as well as other required skills based on their predetermined tasks and a specific command pattern [8]. Khankeh [9] indicated lack of readiness of hospitals and healthcare centers in Iran, and highlighted the need for adequate attention to this issue. Amiri et al. [10] investigated the preparedness of hospitals in Semnan Province in disasters, and reported that $30 \%$ of hospitals had an inadequate preparedness score and $70 \%$ only had moderately prepared.

Disaster management requires managers to make quick decisions, provide a responsible framework and scientific and experience-based management [8]. One of the strategic initiatives for hospitals in dealing with disaster is the implementation of an incident command system [8]. Hospital Incident Command System (HICS) helps the hospitals continue health care delivery in emergencies [3], and provide an effective response to disasters, as a management system, for organizing staff, facilities, equipment and communication. In this system, a single person commands the incident response [8].

With the establishment of this standard system in all hospitals at both local and national levels along with the regular and precise arrangement of human resources and managerial tasks, and development of the unity of command, the management of incidents in hospitals can be improved [4]. In Iran, a limited number of studies have been conducted to investigate the effect of HICS establishment, and to our knowledge, no study has been conducted in simulated conditions. The readiness of medical and management personnel is important in preparation for disasters and accidents [11].

On the other hand, the impact of the HICS establishment on reducing the incidences and physical and financial damages seems to be important in hospitals (especially in military hospitals) to respond quickly and effectively. As a result this study was conducted to investigate the effect of establishing the HICS on preparedness of Iranian law enforcement hospitals in Tehran, using the simulated conditions, in response to crises.

\section{Materials and Methods}

This was a quasi-experimental interventional research. Sampling was conducted using census method in Vali Asr subspecialty Hospital and Imam Sajjad Hospital. The study population consisted of all managers (male and female) of these two hospitals including directors, deputy directors, chief human resources officers, certified nursing assistants, all supervisors, chief nursing officers, medical supply officers, head of logistics, and law enforcement officers.

Using census method, 23 managers were selected from Imam Sajjad Hospital (control group) and 32 from Vali Asr Hospital (experimental group); the total number of participants was 55 We applied the Hospital Preparedness Scale (HPS) designed by Khankeh [9]. This is a national tool for evaluating hospital preparedness for accidents and disasters which is a checklist for responding to hospital emergencies. It consists of 9 subscales, including command and control, communications, safety and security, triage, increased capacity, continuity of vital services, manpower, procurement and logistics, and post-disaster recovery.

Each subscale contains a list of essential actions to help hospital managers and planners in the field of disasters and incidents. It is a 3-point Likert-type scale (1=under review, 2=under implementation, and $3=$ completed). Eventually, general preparedness of the hospital is classified in one of the three levels: poor (93-152), moderate (153-212), and strong (123-273).

The questionnaires were completed by all participants. Then the HICS was established in Vali Asr Hospital (experimental group) and the managers received training 
through incident scenarios under simulated conditions (roundtable training).

The training program lasted for three consecutive days, 2 hours per day and a total of 6 hours. In this program, incident management techniques were taught to the participants and they were encouraged to cooperate with out-of-hospital medical centers in decision-making and analysis on the following fields: performing a prevention program, organizing substitute personnel, various teams of organizational charts, pre-accident missions, immediate responsibilities, medium and long-term responsibilities, familiarizing staff with an overview program, returning to normal situation, and restoration and rehabilitation of all health services. Also, educational materials and conferences were used to familiarize them with the equipment and general knowledge. These activities were conducted in partnership with the staff in the form of a 3-day disaster preparedness workshop and training on the concepts of the incident management system around-the-table.

In this study, the HICS consisted of 9 main members, including commander, senior associate, senior public relations manager, senior security officer, technical/medical specialist, and the officers responsible for operating, planning, support, finance and administration [8].
The participants were explained how to establish the HICS in Vali Asr Hospital and the job descriptions were provided to them at the time of training, and one month later, in the posttest stage, the assigned tasks were evaluated using the HPS tool. The collected data were analyzed in SPSS (V. 18) by performing descriptive statistics (frequency, mean, standard deviation), and independent $t$ test and Chi-square test were used to compare the changes in scales and subscales.

\section{Results}

Demographic characteristics (work experience, educational level), and history of triage and first aid training were compared between two groups. Normality and homogeneity of the groups were analyzed by parametric tests. The majority of participants $(91 \%)$ had a bachelor's degree. The highest work experience among managers were between 16 to 20 years $(34.6 \%)$, and most of them $(61.8 \%)$ had no history of triage and first aids training.

After establishing the system and examining the hospital preparedness by the intervention group, it was found that the scores of hospital preparedness increased in all areas after the intervention. This increase was statistically significant only in four areas of communications, continuity of vital services, manpower, procurement and logistics (Table 1). All indicators show the increase in the preparedness level of the hospital, but the difference was

Table 1. Mean (SD) scores for hospital preparedness dimensions before and after the intervention

\begin{tabular}{|c|c|c|c|c|c|c|c|c|}
\hline \multirow{3}{*}{ Characteristics } & \multicolumn{4}{|c|}{ Control Group } & \multicolumn{4}{|c|}{ Experimental Group } \\
\hline & \multicolumn{2}{|c|}{ Pretest } & \multicolumn{2}{|c|}{ Posttest } & \multicolumn{2}{|c|}{ Pretest } & \multicolumn{2}{|c|}{ Posttest } \\
\hline & Mean & SD & Mean & SD & Mean & SD & Mean & SD \\
\hline Command and control & 13.35 & 4.15 & 12.87 & 3.75 & 1.752 & 4.02 & 13.97 & 4.09 \\
\hline Communications & 17.57 & 4.98 & 17.83 & 5.32 & 16.56 & 4.98 & 21.44 & 4.79 \\
\hline Safety and security & 20.83 & 6.30 & 23 & 6.64 & 20.56 & 6.34 & 25.44 & 6.09 \\
\hline Triage & 19.65 & 6.38 & 19.52 & 6.55 & 19.50 & 6.20 & 24.34 & 5.18 \\
\hline Increased capacity & 23.04 & 6.63 & 24.83 & 6.86 & 22.16 & 6.07 & 29.25 & 6.43 \\
\hline Continuity of vital services & 15.13 & 3.34 & 15.39 & 4.88 & 14.41 & 4.47 & 19.16 & 4.42 \\
\hline Manpower & 28.48 & 5.32 & 29.04 & 8.14 & 27.53 & 7.41 & 35.09 & 7.75 \\
\hline Procurement and logistics & 18.26 & 5.20 & 19.04 & 5.72 & 17.41 & 5.56 & 23.13 & 5.68 \\
\hline Post-disaster recovery & 16.43 & 5.37 & 19.22 & 5.90 & 15.19 & 4.61 & 20.53 & 5.22 \\
\hline Total & 172.65 & 41.53 & 181.17 & 48.54 & 166.06 & 43.08 & 21.342 & 44.78 \\
\hline
\end{tabular}


Table 2. Statistics for work experience, educational level, history of triage and first aid training in two groups

\begin{tabular}{|c|c|c|c|c|c|c|c|}
\hline \multirow{2}{*}{\multicolumn{2}{|c|}{ Characteristics }} & \multicolumn{2}{|c|}{ Control Group } & \multicolumn{2}{|c|}{ Experimental Group } & \multirow{2}{*}{ Tests } & \multirow{2}{*}{ Sig. } \\
\hline & & $\mathbf{N}$ & $\%$ & $\mathbf{N}$ & $\%$ & & \\
\hline \multirow{3}{*}{$\begin{array}{l}\text { Educational } \\
\text { level }\end{array}$} & Bachelor's degree & 21 & 91.4 & 29 & 90.7 & \multirow{3}{*}{$x^{2}$} & \multirow{3}{*}{0.314} \\
\hline & Master's degree & 0 & 0 & 1 & 3.1 & & \\
\hline & $\mathrm{PhD}$ & 2 & 8.6 & 2 & 6.2 & & \\
\hline \multirow{4}{*}{$\begin{array}{l}\text { Work experi- } \\
\text { ence (y) }\end{array}$} & $1-15$ & 2 & 27 & 7 & 22 & \multirow{4}{*}{$\chi^{2}$} & \multirow{4}{*}{0.459} \\
\hline & $16-20$ & 8 & 34 & 11 & 34 & & \\
\hline & $21-25$ & 9 & 39 & 9 & 28 & & \\
\hline & $26-30$ & 0 & 0 & 5 & 16 & & \\
\hline \multirow{2}{*}{$\begin{array}{l}\text { Triage and first } \\
\text { aid training }\end{array}$} & Yes & 9 & 39.5 & 12 & 37.5 & \multirow{2}{*}{$\chi^{2}$} & \multirow{2}{*}{0.9} \\
\hline & No & 14 & 60.5 & 20 & 62.5 & & \\
\hline
\end{tabular}

not significant. Three variables of command and control, safety and security, and post-disaster recovery showed the lowest difference.

According to Table 2, there was no significant difference between two groups in terms of educational level (Sig. $=0.314>0.05)$, work experience $($ Sig. $=0.459>0.05)$, and triage and first aid training (Sig. $=0.9>0.05$ ).
Table 3 presents the Mean (SD) changes in the hospital managers' preparedness scores in various domains after receiving the intervention, compared to the time before the intervention. The mean changes in communications (control group $=0.26$; experimental group $=4.87$ ), continuity of vital services (control group $=0.26$; experimental group=4.75), manpower (control group=0.56; experimental group $=7.56$ ), and procurement and logistics

Table 3. Mean (SD) score of changes in the scores of hospital preparedness dimensions after the intervention

\begin{tabular}{|c|c|c|c|c|c|}
\hline \multirow{3}{*}{ Characteristics } & \multicolumn{4}{|c|}{ Changes in Hospital Preparedness After the Intervention } & \multirow{3}{*}{ Sig. } \\
\hline & \multicolumn{2}{|c|}{ Control Group } & \multicolumn{2}{|c|}{ Experimental Group } & \\
\hline & Mean & SD & Mean & SD & \\
\hline Command and control & -0.47 & 5.56 & 1.21 & 6.22 & 0.302 \\
\hline Communications & 0.26 & 7.97 & 4.87 & 7.87 & 0.038 \\
\hline Safety and security & 2.17 & 10.64 & 4.87 & 9.73 & 0.333 \\
\hline Triage & 0.13 & 11.005 & 4.84 & 9.31 & 0.076 \\
\hline Increased capacity & 1.78 & 11.40 & 7.090 & 9.78 & 0.07 \\
\hline Continuity of vital services & 0.26 & 6.38 & 4.75 & 7.57 & 0.025 \\
\hline Manpower & 0.56 & 10.59 & 7.56 & 12.6 & 0.035 \\
\hline Procurement and logistics & 0.78 & 7.75 & 5.71 & 9.54 & 0.046 \\
\hline Post-disaster recovery & 2.78 & 7.93 & 5.34 & 7.96 & 0.244 \\
\hline Total & 8.52 & 72.77 & 46.28 & 73.73 & 0.065 \\
\hline
\end{tabular}


(control group $=0.78$; experimental group $=5.71$ ) showed a significant difference before and after the intervention $(\mathrm{P}<0.05)$. The changes were not statistically significant, in other scales of hospital preparedness $(\mathrm{P}>0.05)$.

\section{Discussion}

The evaluation of hospital managers' preparedness indicate a significant difference in hospital preparedness for the HICS, before and after its establishment in five domains of communications, continuity of vital services, manpower, procurement and logistics. Since the investigated groups were among the managers of Hospitals affiliated to law enforcement with specific disciplines, the improvement of preparedness in these areas were expected.

In terms of preparedness for command and control, safety and security, triage, increased capacity, and postdisaster recovery, no difference were found before and after the establishment of HICS. The reason for this could be the need for changes in infrastructures, as well as holding operational courses in the form of practical exercises and workshops. Vahedparast et al. [12] on the assessment of hospital disaster preparedness in Bushehr City, reported poor and moderate hospital preparedness in terms of management, communications aspect, respectively.

They aimed to assess the level of preparedness in the general hospitals (not military hospitals), and no interventions were carried out. Based on Yarmohammadian et al. [13] study, a poor relationship exists between hospital managers and crisis team lacks any coordination. Findings of Shojaee et al. [14] with the aim of assessing readiness in the educational hospitals affiliated to Iran University of Medical Sciences to establish communications in the case of incidents, showed that the studied hospitals lack all communication methods (effective communication with the media) and are useless during disaster. Moreover, the level communication was poor during incidents in the hospitals.

The current study shows that the implementation of the HICS improves communication planning at the time of incidents, but the preparedness level of Vali Asr Hospital (where the HICS was established) was low before the intervention, especially in the command and control areas. Salari et al. [15] in their study on the preparedness of public and private hospitals in Shiraz City to deal with unexpected incidents, reported that hospital preparedness in the security, communications and transportation sectors was at moderate level, and with regard to the service, command and management, and human resources sectors, the preparedness level was good. In a study by Djalali et al. (2015) on a Modified Hospital Incident Command System (HICS) model in hospitals in Iran, it was found that management performance in disasters has improved [16].

Hospital preparedness was reported poor in term of admission, and moderate in terms of the emergency room services. In our study, the "increased capacity" score in Vali Asr Hospital did not changed significantly before and after the intervention. On the other hand, the preparedness of this hospital increased significantly in terms of continuity of delivering vital services, manpower, and procurement and logistics. According to Ireland et al. [17], considering the specific circumstances of incidents and disasters such as lack of health facilities, crowded shelters, and disturbance in the provision of services, the use of incident command system and its implementation before the occurrence of incidents increases the readiness and control of contamination and infection.

In the study of Delshad et al. [18] on examining the effect of establishing Early Warning System (EWS) on disaster preparedness of Shahid Motahari Hospital in Tehran, no significant difference was found between before and after establishing ESW in terms of command and control, communications, and triage. They reported an improvement in preparedness level, in respect of safety and security and increased capacity.

On the other hand, the readiness of the hospital was improved in terms of continuity of critical services, human resources, support and logistics management, and post-disaster recovery; but such increase was not statistically significant. In the current study, the difference in communications score between before and after intervention was significant which seems logical, considering the importance of communicating in emergency situations. The reason for non-significant difference in preparedness in command and control, as well as safety and security areas in our study can be related to the law enforcement nature of hospitals which have strict rules and regulations.

In both studies, the dimensions of continuity of critical services, manpower, and procurement and logistics improved after receiving the intervention, but this increase was not significant in Delshad et al. study. Vahedparast et al. [12] reported moderate level of preparedness for supporting, and the post-disaster recovery score increased after the intervention, but the difference was not significant. 
Ameriyon et al. [19] in a study on assessing the preparedness of military hospitals against incidents, argued that weakness in management and communication, structural problems, lack of facilities, and poor human resources management are among the most important problems of hospitals in dealing with incidents.

Amiri et al. [20] on evaluating disaster preparedness of hospitals in Semnan Province, reported an inadequate and moderate level of preparedness. This is consistent with the findings of Vahedparast et al. [12] who reported poor level of preparedness for the hospitals in Bushehr City. According to Barzgar et al. [21] who studied the preparedness of hospitals in Zarand City against incidents, hospitals in Iran have a low level of readiness, and the training and interventions in the field of disaster management seem necessary for them to improve their preparedness in dealing with potential incidents.

Based on the results of Yarmohammadian et al. [13] study, the main obstacles to establishing a HICS are lack of administrative culture for disaster management, excessive decision makings by officials, high costs, lack of support from the authorities and lack of management commitment, poor communication and lack of coordination in the crisis team, lack of a competitive atmosphere for progression and excellence among hospitals, lack of attention to the daily activities of managers, lack of a common management language, constant change in regulations, inadequate education and training, lack of planning, and failure in setting up a disaster planning committee.

\section{Conclusion}

The current study was conducted to investigate disaster preparedness of hospitals affiliated to law enforcement staff in Tehran. In spite of some limitations such as short followup period (due to the military and security nature of the hospitals) and limited number of hospitals, the results show a moderate preparation and coordination in hospitals, and establishment of HICS can increase the readiness of hospitals. Therefore, the implementation and training, as well as practice of this system in the health center are recommended. Long-term interventions in more hospitals are suggested for further research. Meanwhile, comparisons should be made between military, public, and private hospitals.

\section{Ethical Considerations}

\section{Compliance with ethical guidelines}

All ethical principles were considered in this article. The participants were informed about the purpose of the research and its implementation stages; They were also assured about the confidentiality of their information; Moreover, They were allowed to leave the study whenever they wish, and if desired, the results of the research would be available to them.

\section{Funding}

This research did not receive any specific grant from funding agencies in the public, commercial, or not-forprofit sectors.

\section{Conflict of interest}

The authors certify that they have no affiliation with or involvement in any organization or entity with any financial interest, or non-financial interest in the subject matter or materials dismissed in this manuscript.

\section{Acknowledgments}

The authors would like to thank directors and all the staff members at Vali Asr and Imam Sajjad Hospitals for their participation in the study.

\section{References}

[1] Charney RL, Rebmann T, Esguerra CR, Lai CW, Dalawari P. Public perceptions of hospital responsibilities to those presenting without medical injury or illness during a disaster. The Journal of Emergency Medicine. 2013; 45(4):578-84. [DOI:10.1016/j.jemermed.2013.05.010] [PMID]

[2] Vali L, Masood A ,Gabar Beyrami H, Yaghoobian B. [Readiness of hospitals affiliated with Tabriz University of Medical Sciences to face disasters (Persian)]. Journal of Health and Development. 2014; 3(1):62-70.

[3] Djalali A, Castren M, Hosseinijenab V, Khatib M, Ohlen G, Kurland L. Hospital Incident Command System (HICS) performance in Iran; decision making during disasters. Scandinavian Journal of Trauma, Resuscitation and Emergency Medicine. 2012; 20(1):14. [DOI:10.1186/1757-7241-20-14] [PMID] [PMCID]

[4] Djalali A, Castren M, Khankeh H, Gryth D, Radestad M, Öhlen G, et al. Hospital disaster preparedness as measured by functional capacity: A comparison between Iran and Sweden. Prehospital and Disaster Medicine. 2013; 28(05):454-61. [DOI:10.1017/S1049023X13008807] [PMID]

[5] Paganini M, Borrelli F, Cattani J, Ragazzoni L, Djalali A, Carenzo L, et al. Assessment of disaster preparedness among emergency departments in Italian hospitals: A cautious warning for disaster risk reduction and management capacity. Scandinavian Journal of Trauma, Resuscitation and Emergency Medicine. 2016; 24(1):101. [DOI:10.1186/s13049016-0292-6] [PMID] [PMCID] 
[6] Kearns RD, Conlon KM, Valenta AL, Lord GC, Cairns CB, Holmes JH, et al. Disaster planning: The basics of creating a burn mass casualty disaster plan for a burn center. Journal of Burn Care \& Research. 2014; 35(1):1-13. [DOI:10.1097/ BCR.0b013e31829afe25] [PMID]

[7] Daily E, Padjen P, Birnbaum M. A review of competencies developed for disaster healthcare providers: Limitations of current processes and applicability. Prehospital and Disaster Medicine. 2010; 25(05):387-95. [DOI:10.1017/ S1049023X00008438] [PMID]

[8] Borhannejad Z. [The effect of education of hospital incident command system on prepardness of disastrr committee and nurses in zarand hospital (Persian)] [Msc. thesis]. Tehran: University of Social Welfare and Rehabilitation Sciences; 2011.

[9] Khankeh HR. [Hospital preparedness in accidents and disasters (Persian)]. Tehran: University of Social Welfare and Rehabilitation Sciences; 2012.

[10] Amiri M, Chaman R, Raei M, Shirvani SDN, Afkar A. Preparedness of hospitals in north of Iran to deal with disasters. Iranian Red Crescent Medical Journal. 2013; 15(6):519-21. [DOI:10.5812/ircmj.4279] [PMID] [PMCID]

[11] Amanat N, Khankeh H, Hosseini M A, Mohammadi F, Aghighi A, Sadeghi A. [The effect of earthquake preparedness training to male high school students on families (Persian)]. Quarterly Scientific Journal of Rescue and Relief. 2013; 5(3):27-40.

[12] Vahedparast H, Ravanipour M, Hajinezhad F, Kamali F, Gharibi T, Bagherzadeh R. [Assessing hospital disaster preparedness of Bushehr province (Persian)]. Iranian South Medical Journal. 2013; 16(1):69-76.

[13] Yarmohammadian MH, Atighechian G, Shams L, Haghshenas A. Are hospitals ready to response to disasters? Challenges, opportunities and strategies of Hospital Incident Command System (HICS). Journal of Research in Medical Sciences. 2011; 16(8):1070-7. [PMID] [PMCID]

[14] Shojaee P, Maleki M. [Hospitals Preparedness in Iran University of Medical Sciences in Disasters in communications aspect (Persian)]. Quarterly Scientific Journal of Rescue and Relief. 2009; 1(1):1-9.

[15] Salari H, Heidari A, Julaee H, Rahimi S, Shafaghat T. [Shiraz hospitals (public \& private) preparedness in dealing with disasters (Persian)]. Quarterly Scientific Journal of Rescue and Relief. 2011; 2(4):1-10.

[16] Djalali A, Hosseinijenab V, Peyravi M, Nekoei-Moghadam M4, Hosseini B, Schoenthal L, et al. The hospital incident command system: Modified model for hospitals in Iran. PLoS Currents. 2015; 7. [DOI:10.1371/currents.dis.45d66b5258f79c1 678c6728dd920451a] [PMID] [PMCID]

[17] Ireland M, Ea E, Kontzamanis E, Michel C. Integrating disaster preparedness into a community health nursing course: one school's experience. Disaster Management \& Response. 2006; 4(3):72-6. [DOI:10.1016/j.dmr.2006.03.001] [PMID]

[18] Delshad V, Borhani F, Khankeh H, Abbaszadeh A, Sabzalizadeh S, Moradian MJ, et al. The effect of activating early warning system on Motahari hospital preparedness. Health in Emergencies and Disasters. 2015; 1(1):3-8.

[19] Amanat N, Ameriyon A, Aghighi A, Tofighi S, Sadeghi $\mathrm{Aa}$, Shahedi A, et al. [Assess the disaster preparedness of the selected military hospitals (Persian)]. Annals of Military and Health Sciences Research. 2013; 11(4):353-56.

[20] Amiri M, Mohammadi G, Khosravi A, Chaman R, Arabi M, Sadeghi E, et al. [Hospital preparedness of Semnan province to deal with disasters (Persian)]. Journal of Knowledge \& Health. 2011; 6(3):44-9.

[21] Bazregar R, Khankeh H, Ahmadi S, Hosseni M, Rahgozar M, Moradian M. [The evaluation of application of coordination based disaster response model in Rajaye hospital disaster preparedness (Persian). Iranian Journal of Nursing Research. 2013; 29(8):10-18. 
